
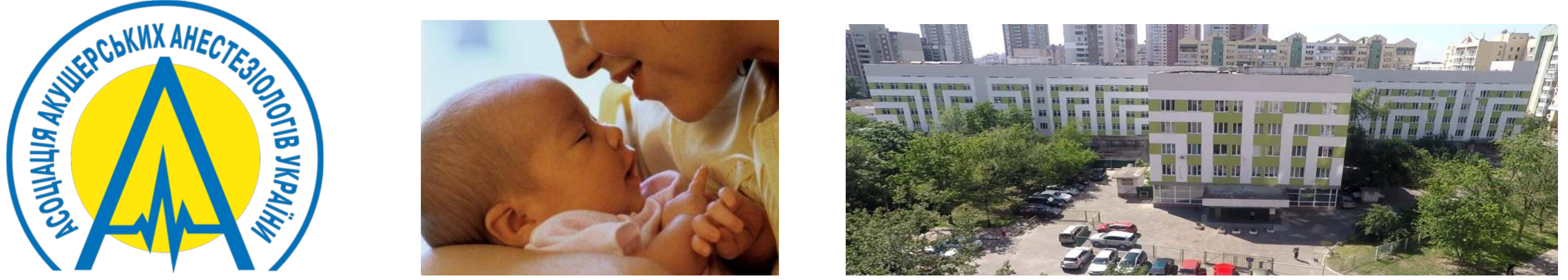

\title{
THE EFFICIENCY OF INTRATHECAL DEXAMETHASONE FOR SPINAL ANAESTHESIA IN ELECTIVE CAESAREAN SECTION
}

Tkachenko R ${ }^{1}$., Pyasetska N. ${ }^{2}$, Petrychenko V. ${ }^{1}$

1 - Shupyk National Medical Academy of Postgraduate Education, Ukraine

2 - Kyiv City Center of Reproductive and Perinatal Medicine, Ukraine

Background: Spinal anaesthesia is commonly used for elective caesarean section. But it has some disadvantages and complications in intra- and postoperative period.

Objective: The aim of this study was to evaluate the efficacy of intrathecal or intravenous dexamethasone to prevent some early complications of spinal anaesthesia such as arterial hypotonia, nausea, vomiting, bradycardia, shivering etc.

Design: We conducted a randomized, prospective, double-blinded, placebo-controlled clinical trial.

Methods: A total of 124 healthy, not obese women, ASA I-II, 18-36 years old undergoing elective cesarean section under spinal anesthesia were divided into three equal groups.

The women of each group received intrathecal hyperbaric bupivacaine $0.5 \% 10 \mathrm{mg}$.

Tabl.1 The review of Distribution of the patients into groups

\begin{tabular}{llll}
\hline Group & N & Base & Adjuvant \\
\hline Group B & 41 & $\begin{array}{l}10 \mathrm{mg} 0.5 \% \\
\text { hyperbar bupi }\end{array}$ & $1 \mathrm{ml}$ normal saline intrathecal \\
\hline Group BD & 42 & $\begin{array}{l}10 \mathrm{mg} 0.5 \% \\
\text { hyperbar bupi }\end{array}$ & $4 \mathrm{mg}$ dexamethasone intrathecal \\
\hline Group D & 43 & $\begin{array}{l}10 \text { mg 0.5\% } \\
\text { hyperbar bupi }\end{array}$ & $\begin{array}{l}8 \mathrm{mg} \text { dexamethasone } \\
\text { intravenouse }\end{array}$ \\
\hline
\end{tabular}

The patients were evaluated for blood pressure, heart rate, nausea, vomiting, shivering or other complications during intra- or postoperative period (24h). The complications that required medicines correction were recorded and treated according to generally accepted protocols.

Results: The addition of intrathecal dexamethasone in Group BD vs Group B significantly decreased frequency and manifestations of arterial hypotonia and nausea (Pearson's $\chi^{2}$ $=0.486$ and $\left.\chi^{2}=0.479, p<0.05\right)$ in intra- and postoperative period after the spinal anaesthesia in elective caesarean section. The addition of intrathecal dexamethasone in Group $B D$ vs Group B significantly reduced shivering (Pearson's $\left.\chi^{2}=0.316, p<0.05\right)$ in intra- and postoperative period, and significantly didn't affect on vomiting and bradycardia. There were no significant difference between intravenous dexamethasone in Group D and placebo in Group B ( $p>0.05)$.

Conclusion: The addition of $4 \mathrm{mg}$ intrathecal dexamethasone as an adjuvant for spinal anaesthesia in elective cesarean section can significantly decrease frequency and manifestations of arterial hypotonia and nausea, reduce shivering during perioperative period. The addition of $8 \mathrm{mg}$ intravenous dexamethasone hasn't the same quality.

Chart.1 The review of Blood Pressure trends in the research groups.

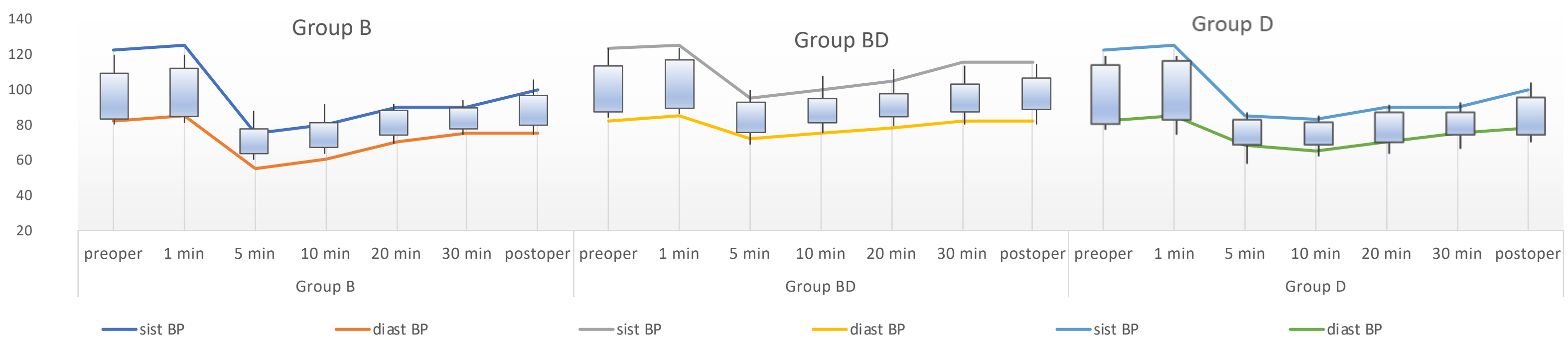

Tab. 2 The review of complications in the research groups.

\begin{tabular}{|c|c|c|c|c|c|c|c|c|c|c|c|}
\hline \multirow{2}{*}{$\begin{array}{l}\text { Complica- } \\
\text { tions* }\end{array}$} & \multirow{2}{*}{$\begin{array}{l}\text { Group B, } \\
n=41\end{array}$} & \multirow{2}{*}{$\begin{array}{l}\text { Group } \\
B D, \\
n=42\end{array}$} & \multirow{2}{*}{$\begin{array}{l}\text { Group D, } \\
n=41\end{array}$} & \multicolumn{2}{|c|}{ Fisher's F- test } & \multicolumn{2}{|c|}{$p$-value } & \multicolumn{2}{|c|}{ Pearson's $\chi^{2}$} & \multicolumn{2}{|c|}{ Efficacy } \\
\hline & & & & B-BD & B-D & $B-B D$ & B-D & B-BD & B-D & B-BD & B-D \\
\hline $\begin{array}{l}\text { Arterial } \\
\text { hypotension }\end{array}$ & 27 & 12 & 22 & 0.0011 & 0.2721 & $<0.05$ & $>0.05$ & 0.486 & 0.175 & Strong & Weak \\
\hline Nausea & 21 & 7 & 16 & 0.0013 & 0.2787 & $<0.05$ & $>0.05$ & 0.479 & 0.172 & Strong & Weak \\
\hline Vomiting & 4 & 1 & 2 & 0.359 & 0.6755 & $>0.05$ & $>0.05$ & 0.214 & 0.132 & Weak & Weak \\
\hline Bradycardia & 12 & 5 & 9 & 0.063 & 0.4626 & $>0.05$ & $>0.05$ & 0.291 & 0.118 & Middle & Weak \\
\hline Shivering & 19 & 10 & 15 & 0.042 & 0.5016 & $<0.05$ & $>0.05$ & 0.316 & 0.139 & Middle & Weak \\
\hline
\end{tabular}

*Complication that required medicines correction 